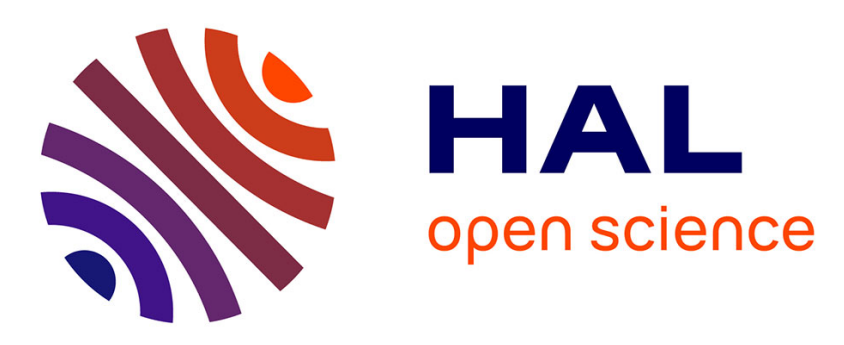

\title{
An review of fully digital audio class $D$ amplifiers topologies
}

Rémy Cellier, Gaël Pillonnet, Angelo Nagari, Nacer Abouchi

\section{To cite this version:}

Rémy Cellier, Gaël Pillonnet, Angelo Nagari, Nacer Abouchi. An review of fully digital audio class D amplifiers topologies. IEEE North-East Workshop on Circuits and Systems, IEEE, 2009, Toulouse, France. pp.4, 10.1109/NEWCAS.2009.5290459 . hal-01103684

\section{HAL Id: hal-01103684 https://hal.science/hal-01103684}

Submitted on 15 Jan 2015

HAL is a multi-disciplinary open access archive for the deposit and dissemination of scientific research documents, whether they are published or not. The documents may come from teaching and research institutions in France or abroad, or from public or private research centers.
L'archive ouverte pluridisciplinaire HAL, est destinée au dépôt et à la diffusion de documents scientifiques de niveau recherche, publiés ou non, émanant des établissements d'enseignement et de recherche français ou étrangers, des laboratoires publics ou privés. 


\title{
An Review of Fully Digital Audio Class D Amplifiers topologies
}

\author{
Rémy Cellier $^{1,2}$, Gaël Pillonnet ${ }^{1}$, Angelo Nagari $^{2}$ and Nacer Abouchi ${ }^{1}$ \\ 1: Institut des Nanotechnologie de Lyon - CPE Lyon, 43 bd du 11 novembre 1918, 69100 Villeurbanne, \\ France,remy.cellier@cpe.fr, gael.pillonnet@cpe.fr,abouchi@cpe.fr \\ 2: STMicroelectronics Wireless, 12 rue Paul Horowitz, 38000 Grenoble, France, remy.cellier@st.com, \\ angelo.nagari@st.com
}

\begin{abstract}
Class D Amplifiers are widely used in portable systems such as mobile phones to achieve high efficiency. This paper presents topologies of full digital class $D$ amplifiers in order to remove the analog $\mathrm{DAC}$ in the amplification path. This approach increases the playback time of embedded system. In first session, open-loop digital class $\mathrm{D}$ and digital modulation are discussed. The characterization of an open-loop class D prototype, using a CMOS $130 \mathrm{~nm}$ ASIC and a FPGA, confirms the advantage of such systems to reach a long battery life. Then, solutions with closed-loop topologies are proposed to increase linearity and power supply rejection of digital class D. Simulation results of closed-loop topologies, showing an increased in sound quality, are presented as well.
\end{abstract}

\section{INTRODUCTION}

The driving factor in research on class $\mathrm{D}$ amplifiers is mainly efficiency. It results in a remarkably high power efficiency of $100 \%$ assuming ideal switching characteristic. This is because the output power MOS operates in the triode and cut-off regions, hereby dissipating very low quiescent power.

Figure 1 shows both solutions for the audio reproduction path in mobile applications. The first topology consists in converting the digital word $x(n)$ to analog and in amplifying with an analog class D power amplifier. This method, called analog class D amplifier, is used for high fidelity audio requirements [1-16] but include a Digital to Analog Converter (DAC). The second architecture replaces the DAC by a PWM digital modulator, called digital class $\mathrm{D}$, to increase the power efficiency conversion. The motivation of the second chain is the architecture simplification in the digital to analog conversion stage.

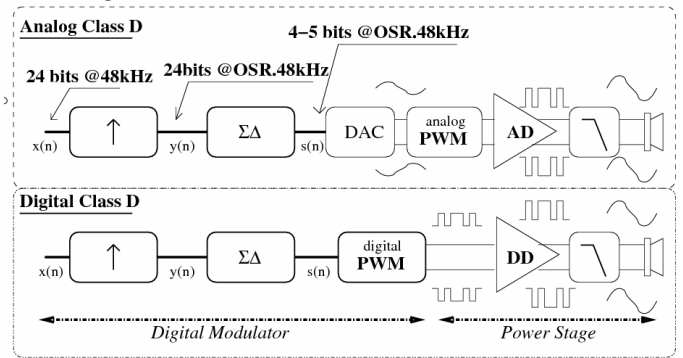

Fig. 1. Analog and digital solutions for class D amplifiers.

In this paper, a Digital Class D Amplifier is studied. For this, in a first step, digital modulators solutions are described. Then, open loop digital class D is analyzed and a prototype is realized. Finally control solutions are proposed to increase the linearity of such systems and to correct errors introduced by the power stage.

\section{Digital Modulator}

\section{A. Direct Digital PWM}

The direct digital PWM topology is illustrated on figure. 2.

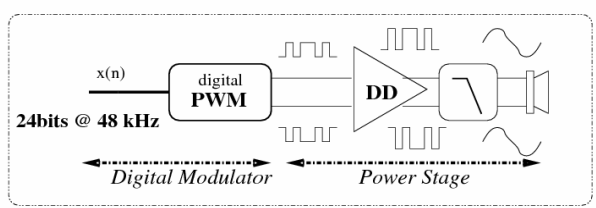

Fig. 2. Direct Digital PWM topology

To drive the power stage DD, the 24 bit input digital word $x(n)$, sampled at $F_{S}$, has to be modulated in pulse width (PWM) in order to create a bit stream waveform. For this, the reference sawtooth signal of PWM have to sweep all the levels of $x(n)$ during the sample time, as shown on Fig. 3.

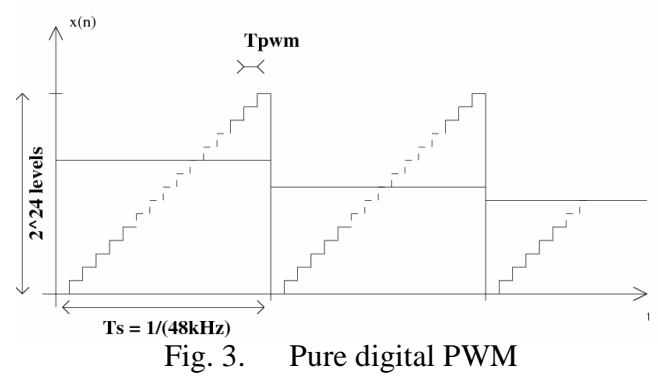

The minimum frequency of the digital sawtooth quantum, which allows to sweep correctly all the levels of $x(n)$, can be expressed as :

$$
\mathrm{F}_{\mathrm{PWM}}=2^{\mathrm{n}} \cdot \mathrm{F}_{\mathrm{S}}=2^{24} \cdot 48 \cdot 10^{3}=805 \mathrm{GHz}
$$

Obviously, such a frequency is not reachable in CMOS technologies. The used of Sigma Delta $(\Sigma \Delta)$ modulation before PWM is necessary to decrease the sawtooth frequency. Indeed, in addition to the shaping of the noise quantification of $x(n)$, $\Sigma \Delta$ modulation reduces the bit-depth of the signal. In this 
implementation, the PWM generator frequency, considering a 5 bits $\Sigma \Delta$ modulator with OSR $=25$, can be expressed as:

$$
\mathrm{F}_{\mathrm{PWM}}=2^{\mathrm{n}} \cdot \text { OSR } \cdot \mathrm{F}_{\mathrm{S}}=2^{5} \cdot 25 \cdot 48 \mathrm{e}^{3}=38 \cdot 4 \mathrm{MHz}
$$

\section{B. $\Sigma \Delta$ modulator topology}

The principles of $\Sigma \Delta$ modulation are the over sampling of the input signal and the shaping of quantification error out of the audio band. A trade-off between performances and complexity is necessary for the $\Sigma \Delta$ topology, depending of the application. For the proposed open loop digital class D, a $5^{\text {th }}$ order modulator with 5 bits of output resolution, and oversampling ratio of 8 are used The Noise Transfer Function $\operatorname{NTF}(z)$ is expressed [17] as :

$$
\operatorname{NTF}(z)=\frac{(z-1)^{5}}{(z+0,082)\left(z^{2}+0,0247 z+0,31\right)^{2}}
$$

The implementation of the proposed $\Sigma \Delta$ is done with a odd order CRFB structure (Fig. 4 shows 3 order modulator).

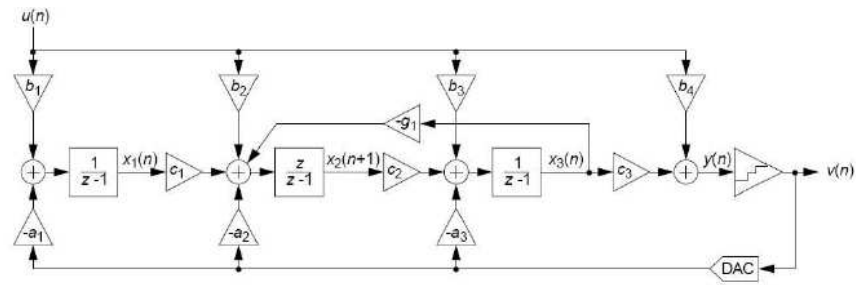

Fig. 4. $\Sigma \Delta$ modulator CRFB structure for odd order

\section{Interpolation of input signal}

The over sampling operation consists in increasing the input sampled frequency by a ratio, called OSR (Over Sampling Ratio). Then, a digital low pass filter is needed to shape audio signal and to avoid folded noise. In addition, for audio application, the reconstitution filter needs to have a linear phase to keep the quality of the audio signal. In this condition, the filter transfer function $\mathrm{H}(\mathrm{z})$ meets the following condition :

$$
\arg \left(H\left(e^{2 j \pi f}\right)\right)=\alpha f
$$

A Finite Impulsive Response filter (FIR) realizes linear phase filter if the coefficients $\mathrm{h}(i)$ are symmetrical with respect to the center of impulse response $\mathrm{N}$ :

$$
h(N-i)=h(N+i)
$$

\section{OPEN LOOP CLASS D TOPOLOGY}

The output stream of the digital modulator has to be translated to drive the output stage as shown on Fig. 5. This level shifting step is necessary to adapt translate the logic levels of $V p(n)$ and $V m(n)$ signals to the power supply $V_{b a t}$ in order to have enough power to drive the load. In our audio application, the load is $8 \Omega$ and $\mathrm{V}_{\text {bat }}=3.6 \mathrm{~V}$.

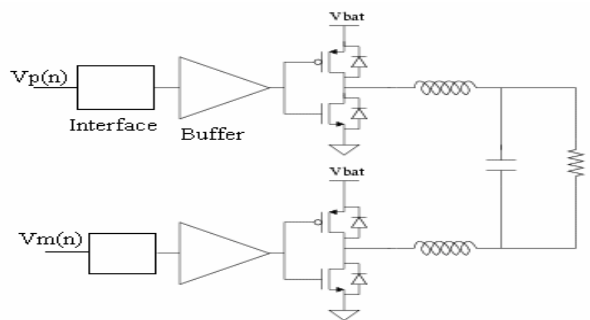

Fig. 5. Output stage of open-loop digital Class D.

The power stage is integrated in $130 \mathrm{~nm}$ CMOS technology (fig. 6) and the digital modulator (i.e. Interpolation, $\Sigma \Delta$ and PWM) is implemented on an Altera FPGA.

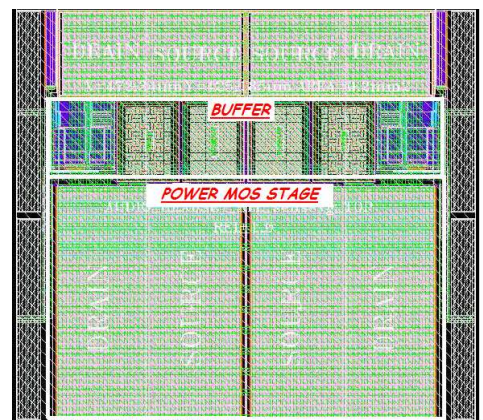

Fig. 6. Digital Open loop Class D topology.

The characterization is in line with simulation results. Table I shows measurements of Total Harmonic Distortion (THD), Power Supply Rejection Ratio (PSRR), Signal to Noise Ration (SNR) and playback time:

\begin{tabular}{|c|c|c|c|}
\hline & $\begin{array}{c}\text { State of } \\
\text { the art }\end{array}$ & $\begin{array}{c}\text { Simulation of } \\
\text { proposed solution }\end{array}$ & $\begin{array}{c}\text { Measurements of } \\
\text { proposed solution }\end{array}$ \\
\hline THD (\%) & 0,1 to 0,01 & 0,01 & $<0,1$ \\
\hline SNR (dB) & 80 to 105 & 101 & 96 \\
\hline PSRR (dB) & 0 to 60 & 0 & 0 \\
\hline $\begin{array}{c}\text { Playback } \\
\text { time (h) }\end{array}$ & 10 to 30 & 80 & 80 \\
\hline
\end{tabular}

Table 1. Comparison with other class $D$ solutions [1-16]

These results confirm the interest of the digital class D approach to increase the playback time of embedded audio systems. However, the major drawback of the open-loop topology is the power supply rejection ratio of $0 \mathrm{~dB}$. Indeed, there is no control of the output voltage and power supply variations are directly introduced to the output signal. In addition, non linear behaviors due to switching are not corrected and increasing consequently the THD.

A feedback system is necessary to have acceptable audio performances. Because of the main errors are due to the power stage, a local feedback loop topology is, in a first time, proposed. 


\section{LOCAL CLOSED LOOP CLASS D TOPOLOGY}

The idea of controlling the output voltage, called local feedback topology, decreases distortion and increases power supply rejection.

\section{A. Local Feedback Loop: State of the art}

Few solutions of local control were already published. In [18], power supply variations are sensed by $\Sigma \Delta$ ADC and a digital controller corrects the bitstream signal and compensates it. This solution, which is complex and expensive because two ADCs are required (one per supply), increases the PSRR up to $60 \mathrm{~dB}$. However, linearity errors of the power stage are not corrected. The THD is too high for high end audio amplifiers.

In [19], an algorithm compares the input bitstream with the output and adds a delay in the input signal to correct errors. Performances are good (THD>80dB, PSSR $>60 \mathrm{~dB}$ ), but the consumption is too high for embedded systems.

In [20], a hybrid approach is proposed. The control loop is both analog and digital. This patented solution [21], is suitable for high power amplifiers. In mobile phones, the output power is too low to use this such of control.

\section{B. Proposed solution: Phase Controlled Loop (PCL)}

A solution based on the control of phases, with a feedback on the output voltage, is proposed on Fig. 7.

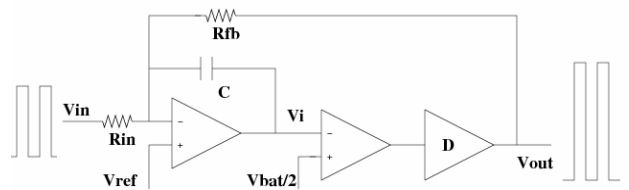

Fig. 7. Phase Control Loop schematic

In steady state, signals $V_{i n}, V_{\text {out }}$ and $V_{i}$ are represented on figure 8 .

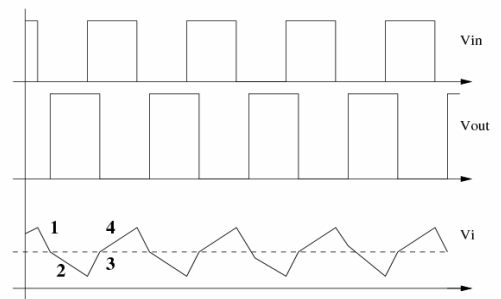

Fig. 8. Input, output and control signals in PCL

The behavior of such a loop can be explained in four distinct phases, due to the pseudo digital nature of signals $V_{\text {in }}$ and $V_{\text {out }}$. During a single phase, $V_{\text {in }}$ and $V_{\text {out }}$ are constant so $R_{\text {in }}$ and $R_{f b}$ are like current sources which charge or discharge $\mathrm{C}$. Depending of the phase (1 to 4 - see Fig. 8), Rin and $R_{f b}$ are current sources or sinks. For example, in phase 1 , both $R_{i n}$ and $R_{f b}$ are current sources, so $\mathrm{U}_{\mathrm{C}}$ is increasing linearly and $V_{i}$ is decreasing linearly too as $U_{C}=V_{\text {ref }}-V_{i}$.

Phases 1 and 3 are called working phases because the output voltage is different from the input voltage, whereas phases 2 and 4 are called waiting phases because the loop is waiting for a new input event.
To work properly, the evolution on $V_{i}$ must not changes when the output signal changes. Indeed, at the end of phase 1, $V_{\text {out }}$ voltage goes from $V_{b a t}$ to ground, which obviously changes $R_{f b}$ current source in a current sink. If this sink is higher than $R_{i n}$ current sources, evolution on $V_{i}$ voltage switches and the loop, instead of going in waiting phase, switches again (Fig. 9). The same issue is possible at the end of phase 3 .

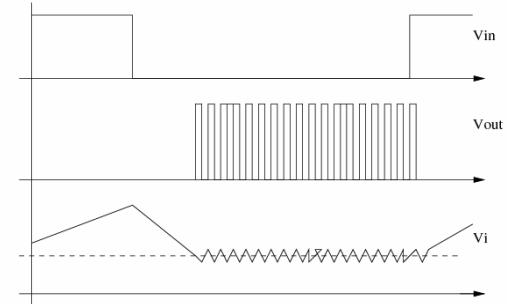

Fig. 9. Inversion of Vi due to wrong ratio of current sources

To avoid this instability at the end of phases 1 and 3, the following condition must be respected:

$$
\frac{R_{f b}}{R_{\text {in }}} \geq \frac{V_{\text {bat }}}{V_{\text {ana }}}
$$

Where $\mathrm{V}_{\text {bat }}$ and $\mathrm{V}_{\text {ana }}$ are supply voltages of the power stage and the digital modulator.

In addition, to insure good linearity, phases $1 / 3$ and $2 / 4$ must be symmetrical. This condition gives the ideal value of reference voltage $\operatorname{Vref}$ :

$$
V_{r e f}=\frac{1}{2} V_{b a t} \frac{R_{i n}}{R_{f b}+R_{i n}}+\frac{1}{2} V_{a n a} \frac{R_{f b}}{R_{f b}+R_{i n}}
$$

The AC model of this loop, modeling the power stage and the commutation stage by a single gain [22] allows the understanding of how the loop gain affects PSRR and linearity. In order to increase performances, the single pole is replaced by a double pole, which increases the gain in low frequencies, such as the audio band and has no consequences in high frequencies.

Two solutions of double pole structure are possible: a single amplifier with two poles in the feedback loop (Fig. 10) or two cascaded amplifiers with a single pole in every feedback loop (Fig. 11).

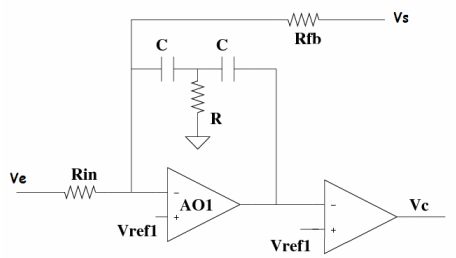

Fig. 10. PCL with one amplifier - double pole schematic

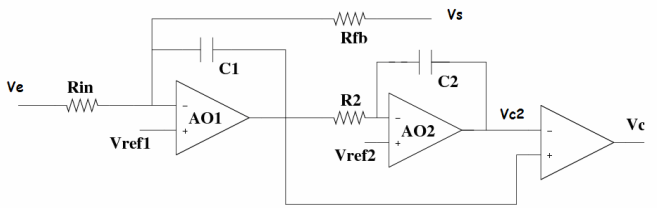

Fig. 11. PCL with two amplifiers - two single poles schematic 
Hence, output voltage of integrator has as expression in both cases:

$$
\begin{aligned}
& V_{C 1}(p)=-\frac{1+2 R C p}{R_{\text {in }} R C^{2} p^{2}} V_{\text {in }}(p)-\frac{1+2 R C p}{R_{f b} R C^{2} p^{2}} V_{\text {out }}(p) \\
& V_{C 2}(p)=-\frac{1+2 R C p}{R_{\text {in }} R_{2} C_{1} C_{2} p^{2}} V_{\text {in }}(p)-\frac{1+2 R C p}{R_{f b} R_{2} C_{1} C_{2} p^{2}} V_{\text {out }}(p)
\end{aligned}
$$

If $\mathrm{C}_{2}=\mathrm{C}, \mathrm{R}_{2}=2 \mathrm{R}$ and $\mathrm{C}_{1}=\mathrm{C} / 2$, the two approaches have the same AC behavior. The second solution reduces the gain bandwidth constraint on the amplifiers, but needs two of them. In addition, the SNR is better for the second solution because the comparison is done with two signals from the integrator, whereas a reference signal is used in the first solution.

Theses two control loops allow good audio performance in both behavioral and electrical simulations (THD > $80 \mathrm{~dB}$, PSSR > $60 \mathrm{~dB}$ and SNR > $100 \mathrm{~dB}$ ). A silicon implementation is forecast to verify theses results.

\section{FULLY CLOSED LOOP CLASS D TOPOLOGY}

To increase the global linearity of fully digital amplifiers, the correction of errors due to the digital modulator can be considered (Fig. 12). The output signal is a bit stream at OSR.F $F_{S}$ with high frequency errors due to the power stage. The bandwidth of the feedback loop ADC has to be very high, which is an issue for the system's consumption and efficiency. The use of a low consumption ADC, as continuous time $\Sigma \Delta$ ADC, could be a potential solution actually on feasibility study.

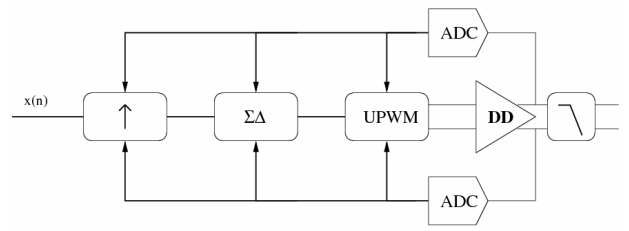

Fig. 12. Global Control of Class D amplifier Topology

\section{CONCLUSION}

The digital class D amplifier is an interesting solution to increase the efficiency of embedded systems such as mobile phones. The realized prototype of the open-loop topology increases the battery life of audio systems by $30 \%$. However, this solution is not good enough in terms of linearity and power supply rejection. An efficient control is needed to correct the error sources. As the major cause of theses perturbations is the power stage, a local feedback topology is proposed at first. The simulated audio performances of this system are equals to analog class D amplifiers (THD>80dB, PSRR $>60 \mathrm{~dB}$, SNR>100 dB). However, a global control with correction of power stage and modulator errors should further increase the linearity.

\section{REFERENCES}

[1] G. Pillonnet, "Intégration d'une chaîne de conversion numérique analogique intégrant une modulation par largeur d'impulsion pour la téléphonie mobile», INL/CPE Lyon/STMicroelectronics, Ph.D Thesis, Nov. 2007

[2] K. Nielsen, "Linearity and Effiency Performance of Switching Audio Power Amplifier Output Stages - A fundamental Analysis", $105^{\text {th }}$ AES Convention, San Francisco, 1998

[3] A. Pietro; N. Flemming; L. Risbo, "Time Domain Analysis of Open Loop Distortion in Class D Amplifier Output Stages", 27th International AES Conference, Sep. 2005

[4] $\mathrm{Wu}$ and al., "Analytical technique for calculating the output harmonics of an H-Bridge inverter with dead time", IEEE Transactions on Fundamental Theory and Applications, Volume 46, Issue 5, p 617-627, may 1999

[5] G. Pillonnet, R. Cellier, N. Abouchi, M. Chiollaz "A high performance switching audio amplifier using sliding mode control" IEEE NEWCAS-TAISA Montreal, Canada, June 2008

[6] E. Gaalaas, BY Liu, N. Nishimura, R Adams, "Integrated stereo $\Delta \Sigma$ class D amplifier", IEEE jouurnal of Solid-State Circuits, Volume 40, Issue 12, p 2388 - 2397, Dec. 2005

[7] L. Soo-Hyoung, S. Jae-Young Shin, L. Ho-Young Lee, A 2W, 92\% efficiency and $0.01 \%$ THD $+\mathrm{N}$ class-D audio power amplifier for mobile applications, based on the novel SCOM architecture", Proceedings of the IEEE Custom Integrated Circuits Conference 2004, p291-294, Oct. 2004

[8] A. R. Oliva, S.S. Ang, T. V. Vo, "A multi-loop voltage feedback filterless class-D switching audio amplifier using unipolar pulsewidth-modulation", IEEE trans. on Consumer Electronics, vol. 50, issue 1, p 312-319, Feb. 2004

[9] K. Nielsen, "High Fidelity PWM based Amplifier Concept for Active Speaker Systems with a very Lower Energy Consumption", 100th AES convention, Copenague, May 1996

[10] P. Midya, B. Roeckner, T. Paulo, "High Performance Digital Feedback for PWM Digital Audio Amplifiers", 121th AES convention, San Francisco, Oct. 2006

[11] J. Tol and co., "A Digitsl class D Amplifier with Power Supply Correction", 121th AES convention, San Francisco, Oct. 2006

[12] T. Ge, M.T. Tan, JS. Chang, "Design and analysis of a micropower low-voltage bang-bang control class D amplifier", IEEE int symp. on Circuits and Systems (ISCAS), p 224-227, May 2005

[13] M. A. Rojas-Gonzalez, E. Sanchez-Sinencio, "Design of Class D Audio Amplifier IC Using Sliding Mode Control and Negative Feedback", IEEE transaction on Consumer electronics, vol. 53, issue 2, p 209-217, June 2007

[14] G. Pillonnet, N. Abouchi, «A Hybrid System Approach for Class D audio Amplifier», $29^{\text {th }}$ Audio Engineering Society (AES) international conference, Sept. 2006, Séoul, South Korea

[15] J.Y. Hung, W. Gao, J.C. Hung, "Variable Struture Control:A Survey", IEEE tranaction on Industrial Electronics, vol. 40, n. 1, Feb. 1993

[16] K. D. Young, U. Ozguner, "Sliding Mode : Control Engineering in Practice", American Control Conferencem San Diego, June 1999

[17] R. Schreier, «Sigma Delta Toolbox», online www.mathworks.com

[18] J. Tol " A Digital Class D Amplifier with power supply correction", $121^{\text {th }}$ AES Convention, Oct 2006

[19] K. Nielsen"Digital Pulse Modulation Amplifier (PMA) topologies based on PEDEC Control", $106^{\text {th }}$ AES Convention, May 8-11 1999

[20] P. Midya "Digital Correction of PWM Switching Amplifiers", IEEE Power Electronics Letters, Vol 2, No 2, June 2004

[21] P. Midya "Switching amplifier having digital correction and method therefore", US Patent 6504 427, Jan. 2003

[22] L. Risbo "A Versatile Discrete Time Approach for Modeling Switch Mode Controllers", IEEE Power Electronics Specialists Conference (PESC), pp. 1008-1014, June 2008 